\title{
Prosodic conditioning of phonetic detail in German plosives
}

\author{
Claudia Kuzla a,b,*, Mirjam Ernestus ${ }^{\text {b,c }}$ \\ a Ludwig-Maximilians-Universität München, Germany \\ ${ }^{\mathrm{b}}$ Max Planck Institute for Psycholinguistics, Nijmegen, The Netherlands \\ ${ }^{\mathrm{c}}$ Radboud University Nijmegen, Nijmegen, The Netherlands
}

\section{A R T I C L E I N F O}

\section{Article history:}

Received 29 August 2008

Received in revised form

12 November 2010

Accepted 4 January 2011

Available online 23 February 2011

\begin{abstract}
A B S T R A C T
This study investigates the prosodic conditioning of phonetic details which are candidate cues to phonological contrasts. German /b, d, g, p, t, k/ were examined in three prosodic positions. Lenis plosives /b, d, g/ were produced with less glottal vibration at larger prosodic boundaries, whereas their VOT showed no effect of prosody. VOT of fortis plosives /p, t, k/ decreased at larger boundaries, as did their burst intensity maximum. Vowels (when measured from consonantal release) following fortis plosives and lenis velars were shorter after larger boundaries. Closure duration, which did not contribute to the fortis/lenis contrast, was heavily affected by prosody. These results support neither of the hitherto proposed accounts of prosodic strengthening (Uniform Strengthening and Feature Enhancement). We propose a different account, stating that the phonological identity of speech sounds remains stable not only within, but also across prosodic positions (contrast-over-prosody hypothesis). Domain-initial strengthening hardly diminishes the contrast between prosodically weak fortis and strong lenis plosives.
\end{abstract}

(c) 2011 Published by Elsevier Ltd.

\section{Introduction}

Part of the variation in the speech signal is induced by the prosodic structure of the utterance. Prosodic structure is the hierarchical organization of spoken language into constituents such as phrases, prosodic words, syllables, etc. (e.g., Nespor \& Vogel, 1986; Selkirk, 1984, 1986; see Shattuck-Hufnagel \& Turk, 1996 for an overview). These constituents, or prosodic domains, are embedded such that a larger prosodic domain comprises one or more next-lower constituents (i.e., a prosodic word consists of syllables, a phrase of prosodic words, and a major phrase or utterance of smaller phrases). Phonetic research in various languages has shown that speech sounds are articulated more strongly at the beginning of prosodic domains than in domainmedial position, that is, they are typically produced with stronger contact between the articulators, with longer gestural durations, and with less coarticulation, though not necessarily simultaneously (e.g., Cho, 2005; Cho \& Keating, 2001, 2009; Fougeron, 2001; Fougeron \& Keating, 1997; Jun, 1998; Keating, Cho, Fougeron, \& Hsu, 2003; Tabain, 2003a, 2003b). This domain-initial prosodic strengthening is cumulative within the prosodic hierarchy, such that word-initial segments which are also in initial position of a phrase are stronger than word-initial, but phrase-medial segments.

\footnotetext{
* Corresponding author at: Institut für Phonetik und Sprachverarbeitung (IPS), Schellingstr. 3/II, D-80799, München, Germany. Tel.: +49 892180 2760; fax: +49892180 5790 .

E-mail address: clakuz@phonetik.uni-muenchen.de (C. Kuzla).
}

In English, for instance, plosives are mostly produced with longer closures, and often also with longer VOT (Voice Onset Time), after a phrase boundary than after just a word boundary (Cho \& Keating, 2009; Choi, 2003; Fougeron \& Keating, 1997; Keating, 1984; Pierrehumbert \& Talkin, 1992).

Importantly, some of the acoustic characteristics affected by prosodic strengthening are also cues to phonological contrasts. For instance, in both English and German, fortis ${ }^{1}$ plosives are known to be produced with longer closures, longer VOT, stronger release noises and shorter preceding vowels (probably only if part of the same prosodic word) and shorter following vowels (as measured from VOT) than lenis plosives, while the presence and importance of these cues varies with segmental environment and position in the word (e.g., Allen \& Miller, 1999; Crystal \& House, 1988; Fischer-Jørgensen, 1976; Jessen, 1998; Kohler, 1984; Lisker, 1986; Peterson \& Lehiste, 1960). Except for the duration of the preceding vowel, and of the following vowel in CV-onsets (where findings are inconsistent), all of these cues to the fortis-lenis distinction have been shown to be affected by domain-initial prosodic strengthening. This raises the question of how prosodic structure and phonological contrast interact in determining the

\footnotetext{
${ }^{1}$ Since [voice] is not a distinctive feature in German plosives (Jessen, 2001), we refer to the phonological opposition between $/ \mathrm{p}, \mathrm{t}, \mathrm{k} /$ and / b, d, g/ as the fortislenis contrast, and reserve the terms "voiced" and "voicing" for phonetically voiced speech sounds, i.e., those produced with glottal vibration. For convenience, we also employ this terminology when referring to the voicing contrast in other languages.
} 
fine phonetic details of fortis and lenis plosives. How do fortis and lenis plosives differ from each other in different prosodic positions? What happens, for instance, to the different cues to a /b/ if it undergoes prosodic strengthening? How do a prosodically strong / b/ and a prosodically weak / $\mathrm{p} /$ differ from each other? This research question relates to the problem that there is no single definition of strengthening (or, its counterpart, lenition; for an extensive discussion, see Bauer (2008)), as there are not yet enough empirical data.

Currently, there are two major accounts of prosodic strengthening. The so-called Uniform Strengthening Account, as put forward as a possible pattern by Cole, Kim, Choi, and HasegawaJohnson (2007), predicts that all plosives are more fortis-like in stronger prosodic positions. Due to the spatio-temporal expansion of articulatory gestures, both $/ \mathrm{b} /$ and $/ \mathrm{p} /$ are produced with a longer closure, with a longer VOT, and a greater intensity of the release noise at higher prosodic boundaries. As a consequence, lenis plosives at low prosodic boundaries differ maximally from fortis plosives at high prosodic boundaries. This hypothesis is supported by the overall strengthening patterns of English plosives. For instance, closure duration is longer for fortis than for lenis plosives, and all plosives are longer in prosodically stronger positions. Voice Onset Time, which is longer for fortis than for lenis plosives, is also longer in prosodically stronger plosives (Cho \& Keating, 2009; Pierrehumbert \& Talkin, 1992; but see Choi, 2003; Cole et al., 2007, who did not find a prosodic position effect). If indeed consonants are more fortis-like in stronger prosodic positions, this would also explain why sound changes such as consonant lenition and deletion occur first in prosodically weak positions, as noted by Fougeron (2001).

The Feature Enhancement Account (e.g., Cho, 2005; Cho \& Jun, 2000; de Jong, 1995), predicts that the contrast between fortis and lenis plosives is more pronounced in prosodically stronger positions. To our knowledge, there is no direct evidence for paradigmatic contrast enhancement in the domain-initial position. However, Cho and McQueen (2005) have interpreted prosodic effects on Dutch obstruents as supporting domain-initial enhancement of phonetic features. Cho and McQueen report shorter VOT for Dutch fortis plosives at larger prosodic boundaries, in contrast to what has been found for English. They relate their findings to an important difference between English and Dutch in the partitioning of the Voice Onset Time dimension. In English, both fortis and lenis plosives typically display positive VOT, which is substantially longer for the voiceless plosives. In Dutch, lenis plosives are produced with prevoicing (i.e., negative VOT), while fortis plosives show positive VOT, although shorter than in English (van Alphen \& Smits, 2004; Slis \& Cohen, 1969). Cho and McQueen argue that English fortis plosives are characterized by the phonetic feature $\{+$ spread glottis (as defined by Halle \& Stevens, 1971), whereas Dutch fortis plosives are $\{$-spread glottis $\}$. The finding that fortis plosives in stronger prosodic positions are produced with longer VOT in English, but with shorter VOT in Dutch would thus be explained as enhancement of language-specific phonetic features, $\{+$ spread glottis $\}$ for English, and $\{-$ spread glottis $\}$ for Dutch. However, this account only explains why the Dutch fortis plosives are produced with shorter VOT at higher prosodic boundaries, but does not explain why the difference between fortis and lenis plosives in VOT is smaller after higher prosodic boundaries in Dutch. Apparently, Cho and McQueen's account holds for phonetic features, but not necessarily for distinctive features $(\{-$ spread glottis $\}$ is not distinctive in Dutch, since it characterizes both fortis and lenis plosives).

Recently, it has been recognized (Cho \& Keating, 2009) that there may exist important differences between the accented position and the domain-initial position. Comparison of accented and unaccented words suggests that cues to paradigmatic contrasts, such as in bear-pear, are enhanced under phrasal accentuation. Domain-initial strengthening, on the other hand, would mainly enhance syntagmatic contrasts, that is, the contrasts between neighboring segments, in particular those between consonants (C) and vowels (V) in CV-onsets (Beckman, Edwards, \& Fletcher, 1992; Cho, 2004, 2005; Cho \& Keating, 2009; Cole et al., 2007; Farnetani \& Vayra, 1996). Obviously, further research is necessary to shed more light on the question of how domaininitial strengthening affects paradigmatic contrasts.

The current study investigates the interplay of prosody and the phonological fortis-lenis contrast in German, another West Germanic language, closely related with both English and Dutch. The cues to the contrast in German are different from those in both English and Dutch, and therefore allow us to evaluate the Uniform Strengthening and the Feature Enhancement accounts of prosodic strengthening.

Depending on the segmental environment and position in the word, there are numerous cues to the fortis-lenis contrast in German (Jessen, 1998, 2001; Kohler, 1984, 1995). The most important cue or 'basic correlate', according to Jessen (1998, 2001), is VOT. As in English, German fortis plosives are produced with considerable aspiration, while the lenis plosives also show positive, but shorter VOT (Fischer-Jørgensen, 1976; Jessen, 1998). In terms of Cho and McQueen (2005), German fortis plosives are therefore characterized by $\{+$ spread glottis $\}$, which is also supported by glottographic data (Butcher, 1977; Fuchs, 2005; see also Jessen \& Ringen, 2002).

One of the non-basic or secondary correlates of the fortis-lenis contrast is the duration of the preceding vowel. Even though this cue is not as important as in English, in German vowels tend to be longer before lenis plosives within the same word as well (as found by Kohler, 1979 for read speech). An additional cue is glottal vibration during the closure. Although glottal vibration ('voicing') is not a necessary correlate of lenis plosives in general, it often occurs in intervocalic position (Fischer-Jørgensen, 1976; Jessen, 1998). Another candidate cue is the intensity of the burst, which has been claimed to be greater for fortis than for lenis plosives (Kohler, 1977, 1995). Other reported cues include the duration of the closure, which is longer for fortis plosives at least in word-medial position, and the fundamental frequency as well as the first formant in the onset of the following vowel, which are both higher after fortis plosives (Jessen, 1998; Kohler, 1982).

The present study investigates word-initial plosives preceded and followed by a vowel. We opted for plosives in CV-onsets, since most research on prosodic strengthening has focused on such simple syllable structures, while little is known on prosodic strengthening in clusters (but see Bombien, Mooshammer, Hoole, \& Kühnert, 2010; Byrd \& Choi, 2010; Fougeron, 1998). The plosives were also preceded by vowels because such a segmental context makes acoustic measurements more precise and avoids coarticulation and assimilation of the target plosive to neighboring consonants. Unfortunately, the choice of preceding context cannot solve the problem that plosive duration cannot be measured in the vicinity of a pause (see Section 2.5 ).

We focused on those cues to the fortis-lenis cues that are likely to be affected by domain-initial prosodic strengthening. Initial strengthening affects mainly consonants, whereas prominence affects both vowels and consonants (Cambier-Langeveld, 2000; Cho \& Keating, 2009; Turk \& Sawusch, 1997). Moreover, initial strengthening effects are strongest in the segments immediately following the prosodic boundary and decay rapidly in subsequent segments. For instance, Cho and Keating (2009) found no boundary effects on vowel duration, first formant frequency and vowel contact in electropalatographic measures in CV syllables, and Bombien et al. (2010) and Byrd and Choi (2010) report 
boundary effects on the duration of the first, but not the second consonant in CCV onsets. We therefore investigated primarily the cues located in the domain-initial consonant, and took only durational measures into account for the surrounding vowels. Following the unfolding speech stream over time, we measured the duration of the preceding vowel, the closure duration, the presence and temporal extent of glottal vibration during the closure, the intensity of the release burst, VOT, and the duration of the following vowel (measured in two ways, from onset of periodicity and from consonantal release). The duration of the following vowel, even though not a well-established cue to the fortis-lenis contrast in German, was included because in English, vowels following word-initial fortis plosives tend to be shorter than those following lenis ones (Allen \& Miller, 1999, who measured vowel duration from onset of periodicity).

Both the Uniform Strengthening Account and the Feature Enhancement Account predict all fortis plosives to be more fortis-like in higher than in lower prosodic domains, that is, to be produced with longer closure durations with less glottal vibration, stronger releases, longer VOT, and shorter following vowels compared to lower domains. The Uniform Strengthening Account makes the same prediction for the lenis plosives, whereas the Feature Enhancement Account predicts lenis plosives in higher prosodic domains to be more lenis like. That would imply shorter closures with more glottal vibration, weaker releases, shorter VOT, and longer following vowels.

\section{Method}

We recorded ten native speakers of German who read sets of meaningful sentences. Embedded in these sentences were the target words, members of three minimal pairs in which the plosives /b/ versus $/ \mathrm{p} /$, /d/ versus $/ \mathrm{t} /$, and $/ \mathrm{g} /$ versus $/ \mathrm{k} /$ occurred in word-initial position. The syntactic structure of the sentences was varied in order to induce different-sized prosodic boundaries before the target words (see Section 2.1). The recordings were prosodically analyzed in order to determine the prosodic boundary strength before the target word (see Section 2.4); thereafter we examined the effect of prosodic boundary strength on the above mentioned acoustic correlates of the fortis-lenis contrast (Sections 2.5 and 3).

\subsection{Speech materials}

Six German words were selected where one of the plosives /b, d, g, p, t, k/ occurred in word-initial position and was followed by $\mid a /$. These words formed three minimal word pairs, of which the members differed only in the fortis/lenis specification of their initial plosives:

(1) backen ['bakən] 'to bake' vs. packen ['pakən] 'to pack',

(2) Dank ['dayk] 'thanks' vs. Tank ['tank] 'tank',

(3) Garten ['ga:tən] 'garden' vs. Karten ['ka:tən] 'cards'.

The words that begin with /b/ and /p/ are verb forms. The words starting with $/ \mathrm{d}, \mathrm{t} / \mathrm{and} / \mathrm{g}, \mathrm{k} /$ were incorporated into nominal compounds, forming their first, modifying parts: Dankschreiben 'letters of thanks', Tankdeckel 'tank caps', Gartenarbeit 'gardening', and Kartenspiele 'card games'. In all these compound words, the primary compound stress fell on the first syllable of the target word. We assume that the incorporation into nominal compounds does not affect the lexical stress patterns of the target words, because the elements of nominal compounds constitute prosodic words in their own (Kohler, 1995).
The target words were embedded in meaningful sentences with four different syntactic structures which will be described in the following (see Table 1). The preceding segmental context was always the diphthong /iv/ in the pronoun wir [vie] 'we'. To prevent a confound of domain-initial strengthening with effects of phrasal accentuation, we induced deaccentuation of the target words by asking speakers to place a contrastive pitch accent on another (non-target) word in the utterance, as indicated in bold in Table 1.

Table 1

Speech materials: Target words 'backen', 'packen', 'Dankschreiben', 'Tankdeckel', 'Gartenarbeit' und 'Kartenspiele' in four sentence types. Pitch-accented (nontarget) words are indicated in bold.

/b/ A Am Samstag wollen wir backen und einkaufen. 'On Saturday, we want to do baking and shopping.'

B Geplant hatten wir, Backen und Einkauf zuerst zu machen. 'Our plan was to do baking and shopping first.'

C Einkaufen müssen wir, backen für morgen, und aufräumen. 'We have to go shopping, bake for tomorrow, and tidy up.'

D Heute segeln wir. Backen kann Anna. 'Today we go sailing. (The) Baking can be done by Anna.'

/p/ A Am Samstag wollen wir packen und einkaufen. 'On Saturday, we want to do packing and shopping.'

B Geplant hatten wir, Packen und Einkauf zuerst zu machen. 'Our plan was to do packing and shopping first.'

C Einkaufen müssen wir, packen für morgen, und aufräumen. 'We have to go shopping, pack for tomorrow, and tidy up.'

D Heute segeln wir. Packen kann Anna. 'Today we go sailing. (The) Packing can be done by Anna.'

/d/ A Am Freitag können wir Dankschreiben drucken lassen. 'On Friday we can have letters of thanks printed.'

B Geplant hatten wir, Dankschreiben drucken zu lassen. 'Our plan was to have letters of thanks printed.'

C Einkaufen müssen wir, Dankschreiben drucken lassen, und aufräumen.

'We have to go shopping, have letters of thanks printed, and tidy up.'

D Heute segeln wir. Dankschreiben kann Anna drucken lassen. 'Today we go sailing. Letters of thanks can Anna have printed.'

/t/ A Am Freitag müssen wir Tankdeckel zuerst besorgen. 'On Friday we have to get tank caps first.'

B Geplant hatten wir, Tankdeckel zuerst zu besorgen. 'Our plan was to get tank caps first.'

C Einkaufen müssen wir, Tankdeckel bestellen, und aufräumen. 'We have to go shopping, order tank caps, and tidy up.'

D Heute segeln wir. Tankdeckel kann Anna besorgen. 'Today we go sailing. Tank caps can Anna get.'

/g/ A Am Samstag können wir Gartenarbeit zusammen machen. 'On Saturday we can do (the) gardening together.'

B Geplant hatten wir, Gartenarbeit zusammen zu machen. 'Our plan was to do (the) gardening together.'

C Einkaufen müssen wir, Gartenarbeit alleine machen, und aufräumen. 'We have to go shopping, do (the) gardening alone, and tidy up.

D Heute segeln wir. Gartenarbeit kann Anna machen. 'Today we go sailing. (The) Gardening can Anna do.

/k/ A Am Freitag wollen wir Kartenspiele ohne Anna machen. 'On Friday we want to play card games without Anna.'

B Geplant hatten wir, Kartenspiele alleine zu machen. 'Our plan was to play card games alone.'

C Einkaufen wollen wir, Kartenspiele alleine machen, und aufräumen. 'We have to go shopping play card games alone, and tidy up.'

D Heute segeln wir. Kartenspiele kann Anna mit euch machen. 'Today we go sailing. Card games can Anna play with you. 
The four sentence types were expected to be produced with various prosodic boundaries before the target words. Note that we do not assume any direct mapping between syntax and higher-level prosodic structure. The actual prosodic realization of each sentence token was classified post-hoc based on a prosodic analysis (see below). In sentences of Type A, the target words belong to the predicate group (headed by the preceding inflected verb form wollen 'want') of which the pronoun wir 'we' forms the grammatical subject. It is unlikely that speakers will produce a prosodic phrase boundary before the target words in sentences of this type and we expect only a prosodic word boundary. In sentences of Types B and $\mathrm{C}$, the syntactic cohesion of the target word with the pronoun is weaker, since the target word heads a complement clause (Type B) or functions as an 'item' in a 'list' of non-finite predicate parts (Type C). This weaker cohesion is also marked in orthography by a comma. In these sentences, we can expect prosodic boundaries larger than a word boundary before the target word, but smaller than, for instance, an Intonation Phrase boundary. We chose two different sentence types to elicit these types of boundaries (Types B and C), because it is unclear from the literature (e.g., Féry, 1993; Fox, 1993; Grabe, 1998) whether they indeed elicit intermediate prosodic boundaries (but see Kuzla, Cho, \& Ernestus, 2007). Finally, a large prosodic boundary can be expected between the syntactically complete sentences in Type $\mathrm{D}$, where orthography requires a period.

\subsection{Participants}

Ten native speakers of northern Standard German, five females and five males, participated in the experiment. All of them had spent their childhood in one of the northern federal states of Germany (Schleswig-Holstein, Niedersachsen, Mecklenburg-Vorpommern, and Brandenburg), and no participant displayed any other regional accent or any speech disorder during a short interview and a reading task. They were all university students, with a mean age of 24 years, and were paid for their participation. Ülzmann (2007) reports local variations within this speaker group, with tendencies towards neutralization of the $/ \mathrm{t} /-/ \mathrm{d} /$ contrast in word-medial intervocalic position for speakers of Schleswig-Holstein origin. However, neutralization is unlikely to occur in our materials, since we focus on word-initial plosives and moreover, neutralization appears to be inhibited by existing lexical contrasts.

\subsection{Recording procedure}

The participants first read the materials silently from paper printouts. They were then recorded while reading the sentences aloud at their normal speech rate, in a fluent and natural way. They were instructed to emphasize words printed in bold, but did not receive any specific instruction on prosodic phrasing. Each sentence was repeated five times by each speaker, in randomized blocks, each consisting of one repetition of the four sentences per plosive. In total, 1200 sentence tokens were recorded. Recordings were made in a sound-attenuated booth with a Sennheiser MD 421 microphone and digitized directly into a computer at a sampling rate of $16 \mathrm{kHz}$.

\subsection{Prosodic categorization}

Given that there is no one-to-one correspondence between syntactic and prosodic structure, we based the classification of prosodic boundaries entirely on temporal and intonational criteria. Research on the perceptual strength of prosodic boundaries (de Pijper \& Sanderman, 1994) has shown that the presence of a pause is sufficient to signal a high prosodic boundary. Another strong indicator of prosodic boundaries above the word level is a nonaccent-lending pitch movement or 'boundary tone'. Prosodic word boundaries typically lack such melodic markers. Combining these criteria, we defined three prosodic categories to which we assigned our data. The Major category was characterized by the presence of a pause and a boundary tone. A pause was assumed to be present if the total period of silence exceeded $150 \mathrm{~ms}$ (see Fig. 1 for the distribution of the total duration of silence preceding the plosives' bursts for the prosodic categories). This value may seem somewhat arbitrary, but appeared to be a threshold in our data, since two native listeners (the first author and another phonetically trained transcriber) independently from each other consistently transcribed a pause in all utterances with silence longer than $150 \mathrm{~ms}$. In addition, 21 tokens (1.8\% of the data) were coded as containing a pause based on the perceptual judgments of these same two independent transcribers. Post-hoc inspection of these tokens suggests that these perceptual judgments are based on the temporal structures of the utterances, and that the shorter periods of silence may be attributed, for instance, to a slightly higher speech rate in these particular utterances. The Minor category was characterized by a boundary tone, but no pause, and the Word category by the absence of both a pause and a boundary tone. These criteria have been applied in other studies before (Bombien et al., 2010; Cho \& McQueen, 2005; Kuzla et al., 2007; Kuzla, Ernestus, \& Mitterer, 2010). The two trained native listeners then coded the boundary tones separately, by listening to the utterances and considering the f0 plots in PRAAT. The agreement among the two labelers was 93\%. Three tokens that remained ambiguous after re-inspection were excluded from analysis, as were 19 accented target words. The final data set consisted of 1178 tokens.

The four sentence types induced indeed the expected variation in prosodic realizations, with considerable differences between speakers in their preferred phrasing strategies in particular for sentence types B and C. In addition, there was also within-speaker variation. The distribution of sentence types over prosodic categories is given in Table 2. In general, sentence type A elicited

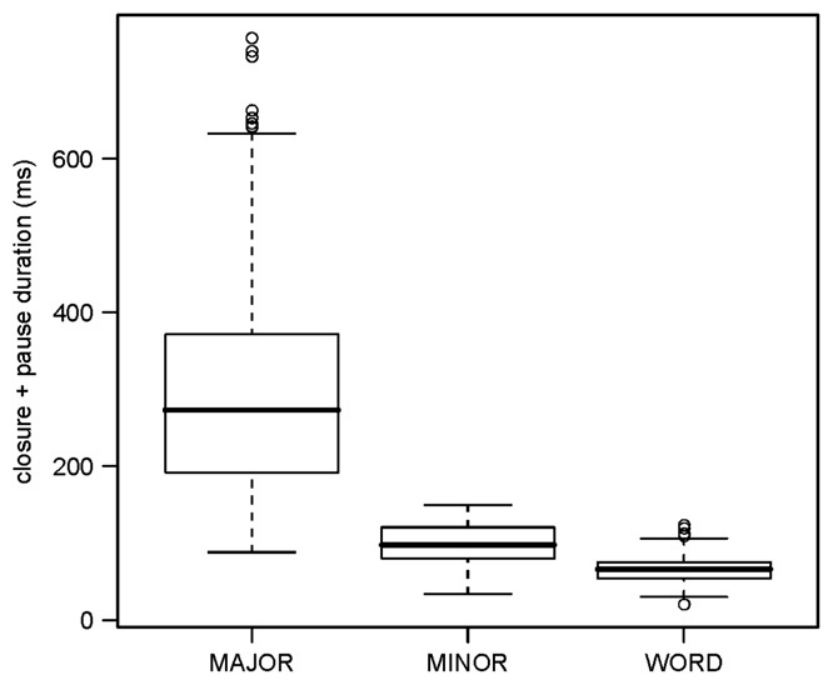

Fig. 1. Distribution of total amount of silence (closure duration plus potential pause in ms) over the three Prosodic Categories.

Table 2

Distribution of sentence types over prosodic categories.

\begin{tabular}{lrrr} 
& Major & Minor & Word \\
\hline Type A: Word & 0 & 2 & 290 \\
Type B: Complement clause & 97 & 181 & 20 \\
Type C: List & 160 & 137 & 2 \\
Type D: Sentence & 228 & 61 & 0 \\
\hline
\end{tabular}


Word boundaries and sentence type D Major boundaries. Types B and $C$ showed more variation, but there was a general preference for Minor boundaries in Type B and a slight preference for Major boundaries in Type $\mathrm{C}$.

\subsection{Acoustic measurements}

A phonetically trained labeler (the first author) annotated the waveforms and spectrograms of the recordings in PRAAT (Boersma, 2001), determining acoustic landmarks in the target word's onset syllable and in the preceding syllable (see Fig. 2 for an example).

First, we measured the duration of the syllable wir /viv/ which preceded the prosodic boundary, for two reasons. First, this duration allows us to evaluate our prosodic classification, since preboundary lengthening is a well-established correlate of prosodic structure (e.g., Wightman, Shattuck-Hufnagel, Ostendorf, \& Price, 1992). If our prosodic categories appear to be good predictors of the duration of the preboundary syllable wir, we take that as external evidence for their validity (the same procedure has been applied in Kuzla et al., 2007). Second, at the same time we can test for an effect of the fortis/lenis contrast on the duration of the preceding vowel. Within words, the duration of the preceding vowel is a cue to the fortis/lenis contrast of the following consonant in German (Kohler, 1977, 1979; Piroth \& Janker, 2004), since (given a constant speech rate, as in our experiment) vowels tend to be shorter before fortis than before lenis consonants. We may find no effect of the phonological contrast in our data, however, since the vowel and the plosive do not belong to the same prosodic word, and to our knowledge, such an effect across word boundaries has never been reported in the literature.

The syllable wir was often realized as a labial approximant followed by a centralized mid-open vowel. As illustrated in Fig. 2, the decay of the vocalic formant structure of the preceding sound in the spectrogram, typically accompanied by lowering of the amplitude in the waveform, was taken as the beginning of the [v]. The onset of formant structure and increased amplitude in the waveform was taken as the beginning of the following vocalic sequence/ir/, often realized as $[\boldsymbol{e}]$. The end of the [ $\mathrm{e}]$ was defined as the offset of formant structure in the spectrogram and, in case of continued voicing, the simpler shape of the periodic signal in the waveform. The duration of these three segments /viv/ was summed up, since the transition from an approximant into a vowel does not allow an exact definition of the segment boundary.

Second, we determined the duration of the stop closure ([g] in the example given in Fig. 2). The beginning of the closure is identical to the end of the preceding vowel in the absence of a pause. In the presence of a pause, the beginning of the closure cannot be determined, and accordingly, we did not study closures preceded by a Major prosodic boundary.

Third, we measured the duration of glottal vibration during the closure. As can be seen on the second tier of the annotation in Fig. 2, the presence of voicing during the closure was defined as periodicity visible in the waveform and in the voice bar of the spectrogram.

Fourth, we measured the VOT, defined as the interval from the closure release, visible as a sudden increase in amplitude after silence in the waveform and in the spectrogram, to the onset of periodicity in the waveform and formant structure in the spectrogram for the following vowel. Fifth, for the fortis plosives, we also extracted the intensity maximum in the first $15 \mathrm{~ms}$ of the release noise (for the lenis plosives, we could not obtain enough reliable measurements because many tokens were produced with weak releases shorter than $15 \mathrm{~ms}$ ). This was done by means of the "Get intensity" function of PRAAT, with the following settings: The time window was $15 \mathrm{~ms}$ from release, the averaging method was $\mathrm{dB}$, the minimum pitch was $120 \mathrm{~Hz}$, and the step size was set to 0 , which implies the time step is automatically computed as one quarter of the effective window length, i.e., as $0.8 /$ (minimum pitch).

Finally, we measured the duration of the following vowel ([a] in Fig. 2) in two ways. First, we measured vowel duration from the onset of periodicity to the decay of formant structure, following, for instance, Allen and Miller (1999), in order to be able to compare our results to previous findings. Second, we measured vowel duration from the release of the plosive to the decay of formant structure, as suggested by Turk, Nakai, and Sugahara (2006).

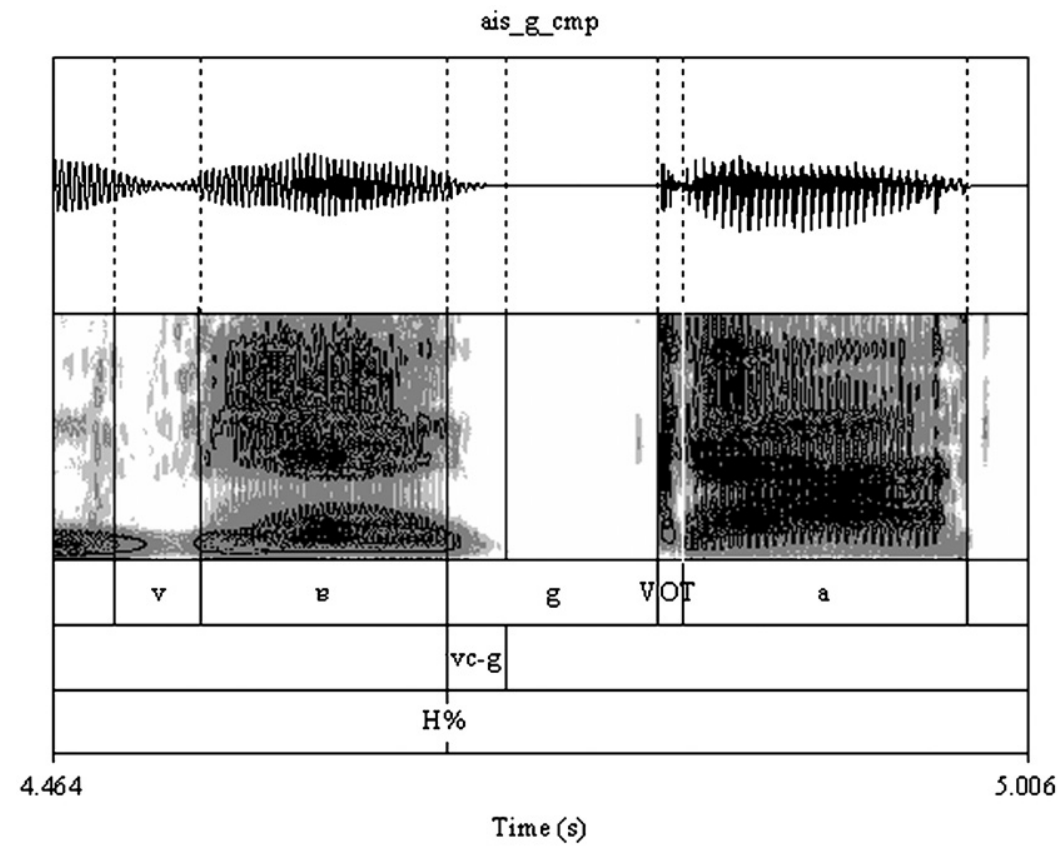

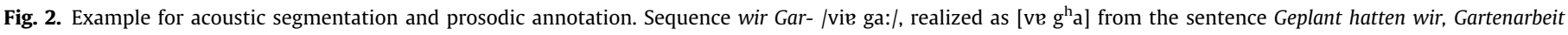

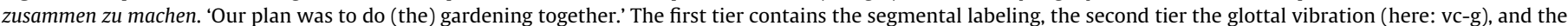
third tier the type of the boundary tone (here: H\%). 


\section{Results}

For all analyses, we built multi-level regression models using contrast coding (e.g., Baayen, 2008; Baayen, Davidson, \& Bates, 2008; Bates, 2005; Dalgaard, 2002) with Prosodic Category (henceforth: PCat; 3 levels: Major, Minor, Word), Place of Articulation (Place; 3 levels: labial, alveolar, velar), and the fortis-lenis contrast (Contrast; 2 levels: fortis, lenis) as fixed factors, and with Speaker as a random variable. This type of statistical model acknowledges the insight that speakers differ considerably in their articulation, including for instance speech rate, amount of glottal vibration, and loudness. This implies that the regression model does not only place the effects of the default values (i.e., the values of the factor levels that happens to start with the letter that is lowest in the alphabet) of the predictors on the intercept, but also a correction for each participant's idiosyncratic behavior. Thus, these models reduce the variance in the data contributed by inter-speaker differences, and are able to detect effects of the fixed factors which might not be captured by a comparison of group means only. The $F$ tests in this type of analysis test for the unique contribution of each factor (once the effects of the preceding factors in the formula have been taken into account).

\subsection{Effects of prosodic boundary}

\subsubsection{Preboundary lengthening}

Analysis of the preboundary syllable duration as a function of PCat, Contrast and Place yielded significant main effects of PCat $(F(2,1160)=1122.9 ; \quad p<0.001)$ and Place $(F(2,1160)=3.2$; $p<0.05$ ), but no effect of Contrast and no interactions. Additional analyses showed that the effect of Place was due to $/ \mathrm{g} /$, for which the preboundary syllable was slightly longer (on average $10 \mathrm{~ms}$, that is, about 6\%) than for the other plosives. Importantly, all prosodic categories differed from each other in the expected direction (all $p<0.001$; means: Major $230 \mathrm{~ms}$, Minor $118 \mathrm{~ms}$, Word $99 \mathrm{~ms}$ ). We take this result as evidence for the validity of our prosodic categorization. That there is no effect of Contrast on preboundary lengthening indicates that in sequences of a vowel and a plosive separated by a prosodic word boundary (V\#C), vowel duration is not a cue to the fortis-lenis contrast, as opposed to the VC\# case.

\subsubsection{Closure duration}

We analyzed the duration of the plosive closure for the prosodic categories Minor and Word only, since the beginning of the closure could not be determined after the pause in the Major condition. PCat $(F(1,681)=508.3 ; p<0.001)$ and Place $(F(2$, $681)=73.6 ; p<0.001)$ emerged as significant, as did the interaction between PCat and Contrast $(F(1,681)=4.0 ; p<0.05)$. To investigate the interaction, we split the data by Contrast. ${ }^{2}$

For fortis plosives, PCat and Place were significant predictors (PCat: $F(1,352)=211.6 ; \quad p<0.001$; Place: $F(2,352)=39.9$; $p<0.001)$. The average closure durations by prosodic category and place of articulation are given in Table 3. As expected, closures were about $31 \%$ longer at the higher prosodic boundary (Minor $98 \mathrm{~ms}$ on average $>$ Word $68 \mathrm{~ms}$ on average). Furthermore, pair-wise comparisons showed that closure duration differed significantly (all $p<0.001$, Bonferroni corrected) between the three places of articulation $(/ \mathrm{p} />/ \mathrm{t} />/ \mathrm{k} /)$.

\footnotetext{
${ }^{2}$ We also split the data by Prosodic Category, instead of Contrast. The analysis showed that Contrast only predicted closure duration for plosives at word boundaries, where lenis plosives had a slightly shorter duration ( $3 \mathrm{~ms}$ shorter on average) than fortis plosives.
}

Table 3

Mean closure duration (ms) of fortis plosives as a function of prosodic category and place of articulation. Standard deviations are given in brackets.

\begin{tabular}{lrrl}
\hline & \multicolumn{1}{l}{ / $/$} & \multicolumn{1}{l}{$/ \mathrm{k} /$} & \multicolumn{1}{l}{} \\
\hline Minor & $107(20.9)$ & $100(20.4)$ & $88(28.0)$ \\
Word & $80(15.8)$ & $69(11.7)$ & $56(13.7)$ \\
\hline
\end{tabular}

\section{Table 4}

Mean closure duration ( $\mathrm{ms}$ ) of lenis plosives as a function of prosodic category and place of articulation. Standard deviations are given in brackets.

\begin{tabular}{lrrl}
\hline & /b/ & /d/ & /g/ \\
\hline Minor & $114(22.2)$ & $100(28.5)$ & $94(26.2)$ \\
Word & $77(13.3)$ & $63(13.2)$ & $55(12.3)$ \\
\hline
\end{tabular}

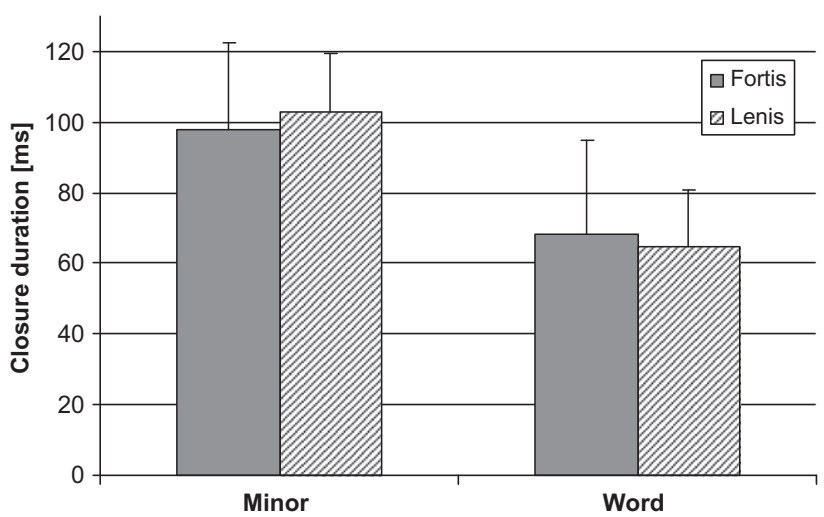

Fig. 3. Closure duration as a function of Prosodic Category and Contrast.

The analysis of the lenis plosives also yielded a main effect of Place $(F(2,329)=32.9 ; p<0.001)$. The three places of articulation differed from each other in the same direction as for the fortis plosives (all $p<0.001 ; / \mathrm{b} />/ \mathrm{d} />/ \mathrm{g} /$ ). Additionally, we observed a main effect of PCat $(F(1,329)=304.8 ; p<0.001)$, with again longer closures in the Minor condition. Means are provided in Table 4. As illustrated in Fig. 3, this effect of prosodic category is slightly larger for the lenis than for the fortis plosives, which explains the interaction in the main analysis.

These findings do not allow us to evaluate the Uniform Strengthening Account and the Feature Enhancement Account, since closure duration does not appear to be a strong correlate of the fortis-lenis contrast of word-initial plosives in production. The analysis showed no main effect of Contrast, and also Jessen (1998) found no effect of closure duration for word-initial plosives, in contrast to word-medial plosives. We will come back to this issue in Sections 3.2 and 4.

\subsubsection{Voice Onset Time}

For Voice Onset Time (Fig. 4), there were main effects of PCat $(F(2,1160)=34.5 ; p<0.001)$, Place $(F(2,1160)=139.3 ; p<0.001)$, and Contrast $(F(1,1160)=4084 ; p<0.001)$, and a significant interaction of PCat and Contrast $(F(2,1160)=25.4 ; p<0.001)$. To investigate this interaction, we split the data again by Contrast and modeled VOT as a function of PCat and Place.

For the fortis plosives, there were significant main effects of PCat $(F(2,583)=28.6 ; p<0.001)$ and Place $(F(2,583)=57.8$; $p<0.001)$. Across all places of articulation, VOT was longest after Word boundaries (mean: $58 \mathrm{~ms}$ ), shorter after Minor boundaries (mean: $53 \mathrm{~ms}$ ), and shortest after Major boundaries (mean: $49 \mathrm{~ms}$ ), with all differences between prosodic conditions being 


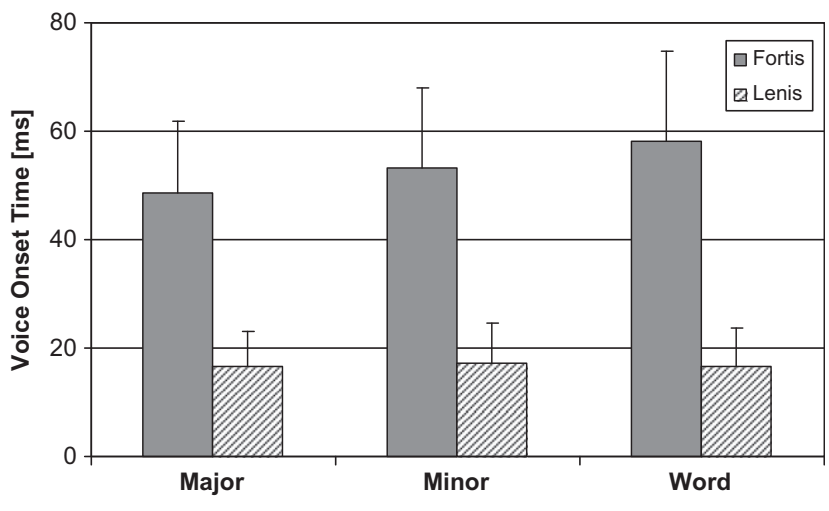

Fig. 4. Voice Onset Time as a function of Prosodic Category and Contrast.

significant (all $p<0.001$ ). Furthermore, pair-wise comparisons showed that VOT was different for the three places of articulation $(/ \mathrm{p} /</ \mathrm{t} /</ \mathrm{k} /$; all $p<0.001)$, mean values being $47 \mathrm{~ms}$ for $/ \mathrm{p} /$, $51 \mathrm{~ms}$ for $/ \mathrm{t} /$, and $60 \mathrm{~ms}$ for $/ \mathrm{k} /$. This order is as expected, given that a larger oral cavity facilitates vocal fold vibration, as it allows for a lower supraglottal pressure during the stop closure phase.

For the lenis plosives, there was no effect of PCat $(F(2$, $585)=1.2 ; p>0.1$, which explains the interaction in the overall analysis. Only the effect of Place was significant $(F(2,585)=227.4$; $p<0.001)$. Pair-wise comparisons revealed that all places of articulation differed from each other (all $p<0.001$ ), showing a pattern of /b/ (mean: $12 \mathrm{~ms}$ ) having a shorter VOT than /d/ (mean: $16 \mathrm{~ms}$ ), both having shorter VOT than /g/ (mean: $22 \mathrm{~ms}$ ), which is the same pattern as for the fortis plosives.

Our finding that VOT for fortis plosives decreases with stronger prosodic boundaries is exactly the opposite of the predictions made by both the Uniform Strengthening Account and the Feature Enhancement Account. The absence of a prosodic effect for lenis plosives is also unexpected under the Uniform Strengthening Account, since, according to this account, all plosives should become more fortis-like in higher prosodic domains, and consequently, VOT should increase for all plosives. We have to conclude that the two accounts do not appear to account well for the effects of domain-initial strengthening in German.

\subsubsection{Intensity of release noise (fortis plosives)}

For the fortis plosives, we analyzed the intensity maximum in $\mathrm{dB}$ during the first $15 \mathrm{~ms}$ of the release noise as a function of PCat and Place. Both factors and the interaction emerged as significant (PCat: $F(2,579)=4.2 ; p<0.05$; Place: $F(2,579)=225.8 ; p<0.001$, PCat: Place: $F(4,579)=3.7 ; p<0.01)$. Mean intensity maximum values by prosodic category and place of articulation are provided in Table 5.

Because of the interaction, we analyzed the effect of PCat separately for each plosive. The effect of prosodic category was absent for $/ \mathrm{p} /(F(2,193)=0.7 ; p>0.1)$, but present for $/ \mathrm{t} /(F(2$, $190)=3.2, p<0.05)$ and $/ \mathrm{k} /(F(2,196)=9.8 ; p<0.001)$. For both $/ \mathrm{t} /$ and $/ \mathrm{k} /$, the release was slightly, but significantly softer (mean difference: 1.4 and $0.8 \mathrm{~dB}$ respectively) in the Major condition than in the Word condition (both $p<0.01$ ). For $/ \mathrm{k} /$ the difference between the Major and the Minor condition was significant as well ( $p<0.001$, mean difference: $1.0 \mathrm{~dB}$ ). Possibly, because of the presence of a pause in our Major prosodic category, less air pressure was built up behind the oral closure, such that the release intensity was lower than in the other prosodic conditions.

Both the Uniform Strengthening Account and the Feature Enhancement Account predict stronger release noises at higher prosodic boundaries, that is, exactly the opposite of what we found for $/ \mathrm{t} /$ and $/ \mathrm{k} /$. These data appear to support our conclusion
Table 5

Mean intensity maximum $(\mathrm{dB})$ of release noise in fortis plosives as a function of prosodic category and place of articulation. Standard deviations are given in brackets.

\begin{tabular}{lccc}
\hline & $/ \mathrm{p} /$ & $/ \mathrm{t} /$ & $/ \mathrm{k} /$ \\
\hline Major & $55.1(4.4)$ & $58.4(3.3)$ & $59.6(3.6)$ \\
Minor & $53.7(3.4)$ & $58.4(3.4)$ & $60.6(5.0)$ \\
Word & $54.2(4.0)$ & $59.2(3.3)$ & $61.5(4.2)$ \\
\hline
\end{tabular}

based on the analysis of VOT (Section 3.1.3) that the two accounts cannot capture well the effect of domain-initial strengthening on plosive releases in German.

\subsubsection{Glottal vibration}

We performed an analysis of the absolute duration of glottal vibration in ms (see Ernestus, Lahey, Verhees, \& Baayen, 2006 for a similar analysis). In a first step, we investigated whether there was an effect of PCat on the duration of glottal vibration. In order to obtain a normal distribution of this variable, we removed all tokens with a duration of glottal vibration of zero, and all tokens in the Major prosodic category, most of which were produced without glottal vibration. We built a linear multi-level regression model of the duration of glottal vibration as a function of PCat, Place of Articulation, and Contrast. As an additional predictor, we entered Closure Duration. We might expect longer plosives to show longer stretches of glottal vibration, just because the time slot where glottal vibration may be present is larger. This would result in a linear positive relation between the absolute duration of glottal vibration and closure duration. However, long stretches of glottal vibration are difficult to produce, because with increasing closure duration, it is harder to maintain a transglottal pressure drop. We therefore expected a non-linear relationship between the absolute duration of glottal vibration and closure duration, and we also added the square of the closure duration as a predictor in the linear regression model. Since PCat was correlated with Closure Duration, we orthogonalized the two predictors by building a logistic regression model to predict PCat from closure duration, and performed the analysis with the residuals of this model instead of PCat itself. If there was an effect of the PCat residuals, this would indicate a genuine, direct effect of PCat on glottal vibration, not merely an effect of PCat on closure duration (which is likely to affect the duration of glottal vibration for aerodynamic reasons). Finally, in order to obtain less skewed distributions of Closure Duration and of Glottal Vibration, these variables were log-transformed. The results are listed in Table 6 .

Importantly, there was no main effect of PCat and no interaction with this factor. We observed an effect of Place of Articulation $(F(2,600)=28.7, p<0.001)$. As expected on the basis of aerodynamic differences due to oral cavity size and supraglottal pressure, there was longer glottal vibration in bilabial and alveolar plosives than in velar plosives. We also found an effect of Contrast $(F(1$, $600)=269, p<0.001$ ), showing that the duration of glottal vibration was longer in lenis than in fortis plosives. This effect of Contrast interacted with Closure Duration $(F(1,600)=20.8, p<0.001)$ and the squared Closure Duration $(F(1,600)=7.7, p<0.01)$. These interactions are explained by the predicted non-linear relationship between duration and glottal vibration, such that lenis plosives of a medium duration were most likely to contain the longest stretch of glottal vibration (see Fig. 5). The effect of Closure Duration was smaller for fortis than for lenis plosives, which is probably a floor effect.

In a second step, we investigated whether the presence versus absence of glottal vibration was affected by PCat. Again, we 


\section{Table 6}

Results of mixed-model analysis of the log-transformed absolute voicing duration (ms) as a function of the residuals of prosodic category (predicted from closure duration), place of articulation, fortis-lenis contrast, the log-transformed closure duration, and the squared log-transformed closure duration (logClosure duration ${ }^{2}$ ). The intercept is for alveolar plosives following Minor boundaries (contrast coding).

\begin{tabular}{|c|c|c|c|}
\hline & Estimate & Std. error & $t$-Value \\
\hline Intercept & 7.26723 & 3.230555 & 2.25 \\
\hline residualPCat $=$ word & 0.00765 & 0.016261 & 0.47 \\
\hline Place $=$ labial & -0.001153 & 0.036299 & -0.032 \\
\hline Place $=$ velar & -0.216697 & 0.036468 & -5.942 \\
\hline Contrast $=$ lenis & -8.485105 & 3.869724 & -2.193 \\
\hline logClosure duration & -2.190221 & 1.488869 & -1.471 \\
\hline $\log C l o s u r e ~ d u r a t i o n^{2}$ & 0.282211 & 0.17131 & 1.647 \\
\hline Contrast $=$ lenis $\times \log$ Closure duration & 4.571055 & 1.789305 & 2.555 \\
\hline Contrast $=$ lenis $\times \log$ Closure duration ${ }^{2}$ & -0.574905 & 0.206298 & -2.787 \\
\hline
\end{tabular}

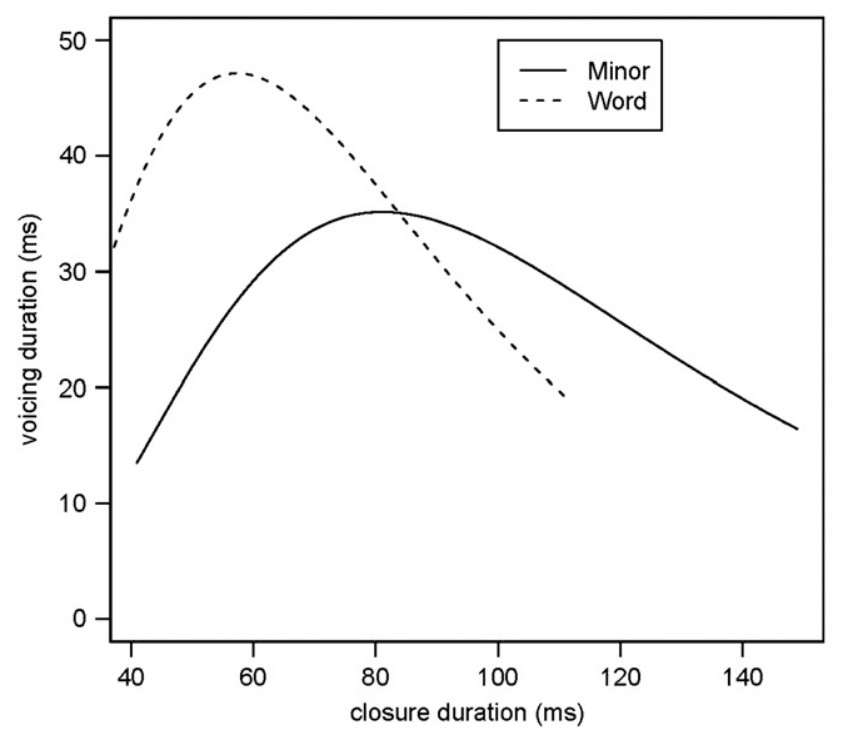

Fig. 5. Correlation of absolute voicing duration and closure duration in plosives for the prosodic conditions Minor and Word. (Place of articulation is alveolar. Mainly the intercept changes for labial and velar plosives; see Table 6.)

restricted ourselves to the data from the Word and the Minor condition, since we could not determine the closure durations in the Major condition. We ran a logistic regression analysis with the logit link function (because of the binary dependent variable), predicting the presence versus absence of glottal vibration as a function of the same factors as tested above. The results are listed in Table 7. We found a main effect of PCat $(F(1,687)=5.3$, $p<0.05$ ), showing that there were more plosive tokens without glottal vibration in the Minor condition (73 out of 381 tokens, i.e., $19 \%$ ) than in the Word condition (10 out of 312 , i.e., $3 \%$ ). In addition, we observed the expected main effect of Contrast $(F(1,687)=6.5, p<0.01$, with $16 \%$ or 58 out of the 358 fortis plosives lacking glottal vibration, but only $7 \%$ or 25 out of the 334 lenis plosives). Finally, the effects of Closure Duration $(F(1,687)=47.7, p<0.001)$ and the square of Closure Duration $(F(1,687)=11.1, p<0.001)$ show that especially the short and the long plosives tended to be realized without glottal vibration, while the plosives with a duration of approximately $40 \mathrm{~ms}$ had the highest probability to be realized with at least some glottal vibration.

In conclusion, plosives following Minor boundaries are more likely to be completely voiceless than plosives following Word

\section{Table 7}

Results of mixed-model analysis of the presence versus absence of glottal vibration as a function of the residuals of prosodic category (predicted from closure duration), fortis-lenis contrast, the log-transformed closure duration, and the squared $\log$-transformed closure duration (logClosure duration ${ }^{2}$ ). The intercept is for fortis plosives following Minor boundaries (contrast coding).

\begin{tabular}{|c|c|c|c|c|}
\hline \multicolumn{5}{|l|}{ Fixed effects } \\
\hline & Estimate & Std. error & $z$-Value & $\operatorname{Pr}(>|z|)$ \\
\hline (Intercept) & 35.6122 & 16.3054 & 2.184 & $0.028957^{*}$ \\
\hline residualPCat $=$ word & -0.5605 & 0.1838 & -3.049 & $0.002294^{* * *}$ \\
\hline Contrast $=$ lenis & -1.0642 & 0.2804 & -3.796 & $0.000147^{* * * *}$ \\
\hline logClosure duration & -20.0753 & 7.4076 & -2.71 & $0.006727^{* * *}$ \\
\hline logClosure duration ${ }^{2}$ & 2.6 & 0.8391 & 3.098 & $0.001945^{* * *}$ \\
\hline
\end{tabular}

boundaries. This finding is in line with the Uniform Strengthening Account, as plosives apparently are more fortis like at the higher prosodic boundary with respect to voicing.

\subsubsection{Duration of the following vowel measured from VOT}

For all plosives, we analyzed the duration of the following vowel as a function of PCat, Contrast and Place. All three factors emerged as significant (PCat: $F(2,1165)=4.4 ; p<0.05$, Contrast: $F(1, \quad 1165)=331.80 ; \quad p<0.001$, Place: $F(2, \quad 1165)=2117.3$; $p<0.001)$, as did the interactions between PCat and Place $(F(4$, $1165)=5.1 ; p<0.001)$ and Contrast and Place $(F(2,1165)=43.3$; $p<0.001)$. To investigate these interactions, we modeled the duration of the following vowel as a function of PCat and Contrast for each place of articulation separately. Contrast was significant in all analyses (all $p<0.001$ ): Vowels following fortis plosives were on average $14 \mathrm{~ms}$ shorter than vowels following lenis plosives (means: $76 \mathrm{~ms}$ versus $90 \mathrm{~ms}$ ). The effect of PCat was present for velars only $(F(2,394)=7.6 ; p<0.001)$. For velars, vowels were significantly longer after prosodic word boundaries (all $p<0.001$ in pair-wise comparisons) than after both Minor and Major phrase boundaries, which did not differ from each other $(p>0.1)$. The mean durations of the following vowel after a velar were $120 \mathrm{~ms}$ for Word boundaries, $115 \mathrm{~ms}$ for Minor and $113 \mathrm{~ms}$ for Major boundaries.

That we observed an effect in the vowels following velars, but not in those following alveolars and labials, may be attributed to the fact that in our materials, vowels following velars had overall longer durations. The vowels in Garten- and Karten- are tense and followed by $/ r /$, which is vocalized in German in postvocalic position, resulting in an open syllable structure, whereas the vowels in backen, packen, Dank- und Tank- are lax and occur in closed syllables. These latter vowels may have been too short for the prosodic boundary effect to emerge.

The attested prosodic effect for vowels following velars is compatible with the Uniform Strengthening Account, which predicts that vowels following both fortis and lenis plosives get shorter at higher boundaries. The result is not in line with the Feature Enhancement Account, as it predicts that domain-initial strengthening leads to shorter vowels after fortis plosives but to longer vowels after lenis plosives, and we did not find an interaction of PCat with Contrast. However, as the prosodic boundary effect is limited to vowels after velars in our data, it does not permit strong conclusions with respect to either account.

3.1.7. Duration of the following vowel measured from release onset

We analyzed the duration of the following vowel also as measured from the consonantal release, again as a function of 
Table 8

Mean vowel duration (ms) as measured from consonantal release as a function of prosodic category, fortis-lenis contrast, and place of articulation. Standard deviations are given in brackets.

\begin{tabular}{|c|c|c|c|c|c|c|}
\hline \multirow{2}{*}{$\begin{array}{l}\text { Place of } \\
\text { articulation } \\
\text { Contrast }\end{array}$} & \multicolumn{2}{|l|}{ Alveolar } & \multicolumn{2}{|l|}{ Labial } & \multicolumn{2}{|l|}{ Velar } \\
\hline & Fortis & Lenis & Fortis & Lenis & Fortis & Lenis \\
\hline \multicolumn{7}{|l|}{ Pcat } \\
\hline Major & $106(15)$ & $88(15)$ & $104(11)$ & 79 (11) & 159 (19) & 145 (13) \\
\hline Minor & $122(13)$ & $90(12)$ & 107 (17) & $80(13)$ & $163(16)$ & $152(12)$ \\
\hline Word & $118(16)$ & 91 (18) & $112(13)$ & $81(10)$ & $174(17)$ & $155(13)$ \\
\hline
\end{tabular}

PCat, Place of Articulation, and Contrast. As in the previous analysis, all three factors emerged as significant (PCat: $F(2,1163)=38.7, p<0.001$; Place: $F(2,1163)=3147.7, p<0.001$; Contrast: $F(1,1163)=982.8, p<0.001)$, as did all the two-way interactions (all $p$-values smaller than 0.001 ). To investigate these interactions, we split the data by Place of Articulation. The main effects of Contrast and PCat were significant in all analyses, and so were all the interactions between them (all $p$-values smaller than 0.05). Table 8 displays the average duration of the vowel following the fortis and lenis consonants in the three prosodic boundary conditions for each place of articulation.

Further analyses revealed that the effect of PCat on the duration of the following vowel was always significant after fortis plosives (all $p$-values smaller than 0.001), whereas after lenis plosives, it was only significant for the velar place of articulation $(p<0.001)$. Vowels following fortis plosives appeared to be always shorter after higher prosodic boundaries. This finding is in line with the results reported in the previous section, and with the Uniform Strengthening Account. The Feature Enhancement Account predicts longer vowels after higher prosodic boundaries following lenis plosives, but for the velar lenis plosives in our data, the effect showed the opposite direction.

\subsection{Predictors of contrast}

The above discussions of the different acoustic cues to the fortis-lenis distinction suggest that neither the Uniform Strengthening Account nor the Feature Enhancement Account can completely explain our data. Possibly prosodic structure does not affect the acoustic cues one by one independently in the direction predicted by the Uniform Strengthening or the Feature Enhancement accounts, but takes into account the relevance of the different cues for the fortis-lenis contrast. In order to evaluate this possibility, we need to know the relevance of these cues.

We investigated which of the examined acoustic characteristics do indeed predict the fortis-lenis distinction, and what their relative contributions are. First, we built a generalized multi-level model, predicting the fortis-lenis specification of the plosives (as intended by the speakers according to the presented stimuli) as a function of closure duration, VOT, glottal vibration, and the duration of the following vowel measured from onset of periodicity (if measured from consonantal release, it would be correlated with VOT), again with Speaker as a random factor. We restricted the data set to the plosives following only Word or Minor boundaries, since closure duration data are not available after pauses in the Major condition. We included PCat as a predictor to see whether the contributions of the acoustic characteristics differ for the prosodic domains. This appeared not to be the case and we will therefore not come back to PCat as a predictor in the analysis. We excluded as fixed predictor the intensity maximum of the burst, as no measurements were obtained for the lenis plosives. Note that the fact that these measurements were successfully carried out for the fortis plosives, but not for the lenis plosives, suggests that burst intensity is a valuable cue to the fortis/lenis distinction.

The role of closure duration in the fortis-lenis contrast is uncertain. Previous studies have shown that it is an important cue for word-medial plosives (Fischer-Jørgensen, 1976; Jessen, 1998). However, its contribution to word-initial, but utterance-medial plosive contrasts may be reduced, as is also suggested by our data reported in Section 3.1.2, which showed no difference in duration between the fortis and lenis plosives following Minor boundaries, and only a very small difference for fortis and lenis plosives following word boundaries.

Voicing is not a necessary, but if present, a sufficient cue to lenis plosives (Jessen, 1998, 2001). We therefore expect an effect of glottal vibration. We also expect an effect of VOT, since it has been shown to be a primary correlate of the fortis-lenis distinction (Fuchs, 2005; Jessen, 1998; Ülzmann, 2007), and because it is longer for fortis than for lenis plosives also in our data (see Section 3.1.3). The duration of the following vowel may play a role, as is also suggested by our data reported in Section 3.1.6.

The analysis showed that there were only two significant predictors: VOT $(F(1,689)=87.3, p<0.001)$ and the duration of the following vowel $(F(1,689)=28.7, p<0.001)$. We found neither an effect of closure duration, nor, more surprisingly, of the duration of glottal vibration (all $p>0.1$ ). We will come back to the absence of an effect of glottal vibration at the end of this section.

We then investigated the source of the effect of the following vowel duration. This effect may result from a complementary division of the time span from the release of the plosive to the end of the vowel between aspiration and vowel. The duration of the following vowel is then negatively related with VOT, and its contribution to the prediction of the contrast may be completely due to this correlation. Indeed there was a significant correlation between the duration of the following vowel and VOT (Pearson correlation, $r=-0.15, p<0.001)$. In order to investigate whether the duration of the following vowel also contributed to the predictability of the contrast independently, we created a new variable that is highly correlated with the duration of the following vowel, but which is not correlated with VOT. We modeled the duration of the following vowel as a function of VOT and called the residuals of this model the duration residuals. The duration residuals show a Pearson correlation of 0.97 with the duration of the following vowel $(p<0.001)$, but a non-significant correlation of almost 0.00001 with VOT. We then modeled the Contrast as a function of VOT and the duration residuals, with Speaker as a random variable. VOT was still a significant predictor $(F(1,689)=85.09, p<0.001)$. More importantly, also the duration residuals emerged as significant $(F(1,689)=28.23, p<0.001)$, which shows that the duration of the following vowel contributes to the voicing contrast, independently from VOT.

Not surprisingly, VOT had a much greater effect. Inspection of the beta coefficients of the fixed effects of the logistic regression model described above showed that the maximal effect of VOT (i.e., the maximal value of VOT multiplied by the beta coefficient, which is the estimated effect of the predictor, see e.g., Chatterjee, Hadi, \& Price, 2000) on the logit of Contrast was 45, whereas the effect of the vowel was much smaller (7). VOT appears thus to be the most important predictor of the fortis-lenis contrast.

We also ran an analysis where we replaced the predictors VOT and vowel duration as measured from onset of periodicity by vowel duration as measured from consonantal release (see Section 3.1.7). Again, we build a multi-level linear regression model with Contrast as the dependent (binary) variable, with closure duration, duration of glottal vibration, duration of the following vowel (now as measured from release) and prosodic 
category as fixed factors, and with speaker as a random factor. Duration of the following vowel $(F(1,689)=53.8, p<0.001)$ and glottal vibration $(F(1,689)=80.2, p<0.001)$ emerged as main effects, whereas all other factors and interactions were nonsignificant. As expected, lenis plosives showed more glottal vibration (33 ms on average) than fortis plosives (19 ms). Somewhat surprisingly, the duration of the following vowel appeared shorter for lenis $(108 \mathrm{~ms})$ than for fortis plosives (134 ms). This may be attributed to the shorter VOT of lenis plosives (and its large effect as shown in the previous analysis), which is now part of the vowel duration.

The interesting insight we gain from this second analysis is that glottal vibration is significant if vowel duration is measured from consonantal release, whereas it is not if both VOT and vowel duration as measured from VOT are predictors (as shown in the first analysis). Apparently, the first model considered VOT as the best predictor and vowel duration as the second best predictor, and the predictive power left for glottal vibration was too small to reach significance. In the second analysis, VOT and vowel duration were combined in a single factor, and since they had opposite effects (longer VOT increases the probability of a fortis plosive, whereas a longer vowel decreases that probability), their separate effects canceled each other partially out. As a consequence, vowel duration (as measured from plosive release) was less predictive and left room for the effect of glottal vibration to reach significance.

These results are interesting with respect to the discussion whether [voice] is a distinctive feature in German plosives. The first analysis suggests that it is not, whereas the second analysis suggests that it is. We would like to argue, in line with Jessen $(1998,2001)$, that [voice] is not a primary cue to the fortis-lenis contrast, but if glottal vibration of a certain duration is present, it supports the lenis category.

\section{General discussion}

The present study investigated the influence of prosodic structure on the phonetic realization of fortis and lenis plosives in German. In particular, we addressed the question how prosodic strengthening affects acoustic cues to the fortis-lenis distinction. In the previous literature, two lines of explanation have been put forward: the Uniform Strengthening Account and the Feature Enhancement Account of prosodic strengthening. While the Uniform Strengthening Account predicts that prosodic strengthening makes both fortis and lenis plosives in general more fortis-like in stronger prosodic positions, the Feature Enhancement Account predicts lenis cues to become stronger for the lenis plosives, and fortis cues to become stronger for fortis plosives.
Our data consisted of sentences read by ten speakers, with different prosodic boundaries before the word-initial plosives. We investigated the durations of the preceding vowel, of the consonant closure, of the following vowel and VOT for both the fortis and lenis plosives as well as the amount of glottal vibration (in relative as well as absolute measures), and the burst intensity maximum in fortis plosives. All these measures showed main effects of prosody, as indicated in Table 9 and in the first two columns of Table 10 .

Before we interpreted the results, we investigated whether all analyzed acoustic characteristics are indeed cues to the fortis/lenis distinction in German. We built a model predicting the Contrast value (fortis/lenis) of the plosive as intended by the speaker. The results are summarized in Table 11. All acoustic characteristics appeared to be correlated with this fortis/lenis value, except the duration of the closure. The absence of a correlation for closure duration is in line with earlier findings by Jessen (1998) for wordinitial plosives and suggests that closure duration is only an acoustic cue for the fortis/lenis identity of plosives in word-medial position in German. Among the acoustic characteristics that are cueing the fortis/lenis distinction, VOT appeared most important.

We will now discuss the prosodic effects on the four characteristics that are cues to the fortis/lenis distinction and their implications for the Uniform Strengthening Account and the Feature Enhancement Account (see the two right most columns of Table 10). Note that we wrote "inconclusive" in this table if the acoustic characteristic appeared not to cue the fortis/lenis distinction, or if the accounts do not make predictions for these characteristics.

First, VOT decreased at higher boundaries for fortis plosives, whereas it was not affected by prosodic boundary size for lenis plosives. The decrease in VOT for fortis plosives is unexpected under the Uniform Strengthening and the Feature Enhancement accounts. It is true that our results are similar to the findings for Dutch reported by Cho and McQueen (2005), but in German, fortis plosives are assumed to be specified by $\{+$ spread glottis\}, in contrast to $\{$-spread glottis $\}$ in Dutch. Together with the null effect of prosody on VOT in lenis plosives, this pattern implies contrast diminishing rather than contrast enhancement at higher prosodic boundaries.

Second, we observed slightly higher burst maxima in lower prosodic domains, in contrast to the predictions by both the Uniform Strengthening and the Feature Enhancement accounts. Interestingly, a similar result has been reported for English by Cho and Keating (2009), who measured high-pass filtered RMS energy in $/ t /$. These authors attribute the higher burst energy found at smaller boundaries to possible inverse correlations between the burst amplitude and other properties of the preceding closure

Table 9

Mean values of acoustic measurements for the prosodic categories, and whether the difference between the mean values is statistically significant

\begin{tabular}{|c|c|c|c|c|}
\hline \multirow[t]{2}{*}{ Acoustic measure } & \multicolumn{4}{|c|}{ Mean values for the prosodic categories } \\
\hline & Major & Minor & Word & Significance \\
\hline Duration of preceding vowel & n.a. & n.a. & n.a. & $* * \cdots, \mathrm{a}$ \\
\hline Closure duration (ms) & n.a. & 100 & 66 & $* * * k$ \\
\hline Voice Onset Time (for fortis only) (ms) & 49 & 53 & 58 & $* * * *$ \\
\hline Intensity of release (for fortis only) ( $d B$ ) & 57.6 & 57.7 & 58.4 & * (Word > Major $)$ \\
\hline Glottal vibration (absence) (\%) & n.a. & 19 & 3 & $*$ \\
\hline Duration of following vowel (measured from VOT, for velars only) (ms) & 113 & 115 & 120 & $*$ \\
\hline Duration of following vowel (measured from release, for all places of articulation) (ms) & 113 & 121 & 123 & $*$ \\
\hline
\end{tabular}

n.s. = not significant; n.a. = not applicable to the data presented in this study.

$* p<0.05$

**** $p<0.001$.

a Preboundary lengthening, i.e., duration of the preceding syllable, was taken as a validation criterion for prosodic categorization. 
Table 10

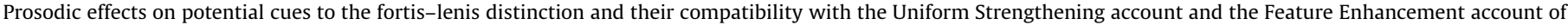
prosodic strengthening.

\begin{tabular}{|c|c|c|c|}
\hline Acoustic measure & Prosodic effect & $\begin{array}{l}\text { Uniform } \\
\text { Strengthening }\end{array}$ & $\begin{array}{l}\text { Feature } \\
\text { Enhancement }\end{array}$ \\
\hline Closure duration & Longer at higher boundaries & inconclusive & inconclusive \\
\hline VOT & Shorter for $/ \mathrm{p}, \mathrm{t}, \mathrm{k} /$ at higher boundaries & contra & contra \\
\hline Burst intensity & Lower at higher boundaries & contra & contra \\
\hline Glottal vibration & Less frequently present at higher boundaries & pro & contra \\
\hline Duration of following vowel measured from VOT & Longer at smaller boundaries (for velars only) & pro, if not inconclusive & inconclusive \\
\hline $\begin{array}{l}\text { Duration of following vowel measured from } \\
\text { release }\end{array}$ & Longer at smaller boundaries for all fortis and for velar lenis plosives & pro & contra \\
\hline
\end{tabular}

Table 11

Mean values of acoustic measurements for fortis and lenis plosives, and whether the difference between the mean values is statistically significant.

\begin{tabular}{|c|c|c|c|}
\hline \multirow[t]{2}{*}{ Acoustic measure } & \multicolumn{3}{|c|}{ Mean values for the contrast categories } \\
\hline & Fortis & Lenis & Significance \\
\hline Closure duration (ms) & 85 & 85 & n.s. \\
\hline Voice Onset Time (ms) & 53 & 17 & $* * * *$ \\
\hline Intensity of release & n.a. ${ }^{a}$ & & \\
\hline Glottal vibration (ms) & 19 & 33 & $* * * *$ in the 2 nd analysis \\
\hline Duration of following vowel (measured from VOT) (ms) & 76 & 90 & $* * *$ \\
\hline Duration of following vowel (measured from consonantal release) (ms) & 133 & 108 & $* * *$ \\
\hline
\end{tabular}

n.s.= not significant; n.a. = not applicable to the data presented in this study.

**** $p<0.001$.

${ }^{a}$ Intensity of release could not be measured for lenis plosives in our data, but is probably a predictor of contrast, too.

which may have undergone articulatory strengthening, such as amount of articulatory contact and velocity of the tongue release. This would make burst maximum results inconclusive for the evaluation of the two prosodic strengthening accounts, as we can only speculate about the involved articulatory gestures.

Third, we found that the likelihood for the occurrence of glottal vibration was higher for plosives following word boundaries. Importantly, this effect was independent of the effect of closure duration on the likelihood of glottal vibration. Glottal vibration is not considered a necessary cue for the fortis/lenis distinction in German plosives (that is why there is no distinctive feature [voice]), but nevertheless it contributes to the perception of the fortis/lenis contrast (e.g., Jessen, 1998). Glottal vibration enhances the lenis character of plosives. In contrast to the predictions of the Feature Enhancement Account, but in line with the Uniform Strengthening Account, we thus see that the more frequent absence of glottal vibration makes lenis plosives less lenis like in prosodically stronger locations.

Finally, the duration of the following vowel if measured from onset of periodicity was hardly affected by prosodic structure. We observed longer vowel durations after smaller prosodic boundaries only for velars. It has been observed previously (e.g., Cho, 2005; Cho \& Keating, 2009; Fougeron, 2001; Fougeron \& Keating, 1997 ) that domain-initial strengthening may be located primarily in the very initial segment after the prosodic boundary and that the effects decay rapidly in the following segments. The direction of the effect in the vowels following velars is unexpected under a simple domain-initial strengthening account, which predicts that segments are strengthened if they are close to a stronger prosodic boundary: Temporal expansion at higher prosodic boundaries would lead to longer vowel durations, which is the opposite of what we found. However, the result is in line with the Uniform Strengthening Hypothesis if we take into account that vowels following fortis plosives tend to be shorter than those following lenis plosives (see our analysis in Section 3.2 and the findings by
Allen \& Miller, 1999): Prosodically stronger boundaries lead to vowel durations which are more typical for fortis plosives.

When vowel duration was measured from oral release, the prosodic effect emerged for all fortis plosives, and for $/ \mathrm{g} /$. Again, vowel durations were shorter after higher prosodic boundaries. All conclusions drawn on the results based on vowel duration as measured from onset of periodicity are further supported by this analysis.

Overall, our findings do not consistently support either of the two accounts of prosodic strengthening. We also considered whether our data could be explained by a third, "durational" hypothesis, whereby prosodic boundary strength primarily affects closure duration, and the other attested effects are merely consequences of this effect of prosody on closure duration. For example, this hypothesis can account for shorter VOTs at higher prosodic boundaries if the glottal opening gesture is aligned with respect to stop closure onset (or mid-point), rather than release, such that more of the glottal opening gesture is overlapped by the stop closure at higher boundaries. This hypothesis, however, cannot account for all our findings. For instance, our analysis in Section 3.1.5 showed that the effect of prosodic boundary on the amount of glottal vibration cannot be entirely ascribed to longer closure duration at higher boundaries.

Rather, we see that prosodic structure does not affect the individual cues in a uniform way. That is, some acoustic characteristics suggest that plosives (either lenis or fortis) are more fortis like after stronger prosodic boundaries (e.g., the shorter duration of the vowel following velars, the smaller likelihood of glottal vibration), whereas other cues make the fortis plosives more lenis like (lower burst intensity and shorter VOT). As a result of this, contrasts appear to be maintained in general, not only within a given prosodic position, but also across positions.

Recently, Cole et al. (2007) have found also that prosodic strengthening is generally contrast-preserving. In their data of four Radio News speakers, accent strengthening effects were 
greatest for those acoustic properties that play smaller roles in encoding phonological contrasts. They concluded that acoustic properties which carry a heavy functional load in terms of phonological contrasts are less free to serve pragmatic functions and are therefore also less susceptible to prosodically conditioned variation induced by phrasal accentuation (see also Berinstein, 1979 for similar findings on cues to lexical stress). Cole et al. (2007) formulated this as a principle of 'phonology-overpragmatics'.

This hypothesis can be extended to domain-initial strengthening. Possibly, domain-initial strengthening also affects especially those characteristics of the acoustic signal that are not highly relevant for distinguishing between phonological contrasts. We will refer to this hypothesis as the contrast-over-prosody hypothesis.

According to our results presented in Section 3.2, the acoustic correlates of the fortis/lenis contrast are VOT, following vowel duration, glottal vibration, and presumably, the intensity maximum of the burst (we did not test this latter cue, but given that it could only be measured for fortis plosives, it is evident that it distinguishes between fortis and lenis plosives). The contrastover-prosody hypothesis predicts that there are only limited prosodic effects on these correlates. On the other hand, duration of the preceding (preboundary) vowel, and closure duration appear not to contribute to the fortis-lenis distinction, and thus the contrast-over-prosody hypothesis predicts that the prosodic effects on these acoustic characteristics of the signal are greater (assuming that they do not cue other important phonological contrasts).

The two measured acoustic characteristics that do not contribute to the fortis/lenis distinction, the duration of the preceding vowel and the closure duration, showed huge effects of prosodic boundary size. While the plosives following a Minor boundary had an average closure of approximately $100 \mathrm{~ms}$, those following only Word boundaries were on average even shorter than $70 \mathrm{~ms}$. Likewise, the preceding vowel was about 20\% longer before Minor and even 30\% longer before Major boundaries than before Word boundaries.

In contrast, VOT, the most important cue to the fortis/lenis distinction according to our analysis, showed only limited prosodic effects. The effect was restricted to fortis plosives and the effect size was $8 \%$. Also on the burst intensity maximum, there was only little prosodically conditioned variation. While there was no effect for bilabials at all, the mean differences between neighboring prosodic categories ranged from 0.8 to $1.0 \mathrm{~dB}$ for alveolars and velars. Finally, also the following vowel duration showed just a minimal effect of prosody (differences of 2-5 ms between prosodic categories), and the effect was restricted to vowels following velars, possibly because these vowels were rather long in our experiment.

On glottal vibration, in contrast, there was a huge effect of prosodic position, and it is indeed a question how relevant glottal vibration is for the fortis/lenis distinction in German. Glottal vibration is considered a sufficient but not a necessary cue. This is supported by our data which shows that $42 \%$ of all lenis plosives were produced without any glottal vibration (with the Major condition already being excluded).

Our findings thus appear in line with the contrast-overprosody hypothesis. Prosody affects especially those acoustic characteristics that do not contribute to phonological contrasts. As a consequence, prosody hardly affects the perceptual distinction between fortis and lenis plosives. Our findings are also well compatible with those of Nakai, Kunnari, Turk, Suomi, and Ylitalo (2009), who also showed that both contrast and prosody are effectively marked, and that phonemic contrast does not overrule the cues to prosodic structure.
The question now is why the minimal prosodic effects that we observe for the relevant fortis/lenis cues appear to diminish the contrast in higher prosodic positions (which is the opposite of the predictions made by the Uniform Strengthening Account and the Feature Enhancement Account). So far, we have only considered the acoustic characteristics of the fortis and lenis plosives in the different prosodic conditions without taking into account whether listeners are able to hear the differences that we observed. Some of the acoustic correlates may not be well perceivable, especially after Word boundaries. For instance, glottal vibration and burst intensity may be masked by the preceding vowel in the short plosives following word boundaries. As a consequence, the acoustic variation in these cues may be unconstrained. This would explain the unexpected direction of some of the attested prosodic effects. Further research is necessary here.

In addition, future research should address the question how the results reported in this paper generalize to other minimal word pairs, to words that are not members of minimal word pairs, to reading tasks including filler material, and to different speech styles. Such studies would show how prosodic categories and segmental contrasts affect acoustic variables in different conditions.

In conclusion, our data suggest that domain-initial strengthening affects especially those cues that are not highly relevant for signaling phonological contrasts (confirming the contrast-overprosody hypothesis and in line with the findings by Berinstein (1979) and Nakai et al. (2009)). The small prosodic effects that we do observe on highly relevant cues do not reflect domain-initial strengthening in the form of either the Uniform Strengthening or the Feature Enhancement Account. Rather, the acoustic cues divide labor in cueing phonemic contrast and prosodic structure.

\section{Acknowledgments}

This research was supported by the Max Planck Gesellschaft zur Förderung der Wissenschaften. We would like to thank Herbert Fuchs, Marianne Radel, and Holger Mitterer for assistance with data collection, coding, and advice on PRAAT scripting, respectively. Furthermore, we are grateful to Taehong Cho, Anne Cutler, Vincent van Heuven, Jennifer Cole, an anonymous reviewer, and the Associate Editor for helpful comments.

\section{References}

Allen, J. S., \& Miller, J. L. (1999). Effects of syllable-initial voicing and speaking rate on the temporal characteristics of monosyllabic words. Journal of the Acoustical Society of America, 106, 2031-2039.

van Alphen, P. M., \& Smits, R. (2004). Acoustical and perceptual analysis of the voicing distinction in Dutch initial plosives: The role of prevoicing. Journal of Phonetics, 32, 455-491.

Baayen, R. H. (2008). Analyzing linguistic data. A practical introduction to statistics Cambridge: Cambridge University Press.

Baayen, R. H., Davidson, D. J., \& Bates, D. M. (2008). Mixed-effects modeling with crossed random effects for subjects and items. Journal of Memory and Language, 59, 390-412.

Bates, D. M. (2005). Fitting linear mixed models in R. $R$ News, 5, 27-30.

Bauer, L. (2008). Lenition revisited. Journal of Linguistics, 44, 605-624.

Beckman, M. E., Edwards, J., \& Fletcher, J. (1992). Prosodic structure and tempo in a sonority model of articulatory dynamics. In G. J. Docherty, \& D. R. Ladd (Eds.) Papers in laboratory phonology II (pp. 68-86). Cambridge: Cambridge University Press.

Berinstein, A. E. (1979). A cross-linguistic study on the perception and production of stress. UCLA Working Papers in Phonetics, 47, 1-59.

Boersma, P. (2001). PRAAT, a system for doing phonetics by computer. Glot International, 5, 341-345.

Bombien, L., Mooshammer, C., Hoole, P., \& Kühnert, B. (2010). Prosodic and segmental effects on EPG contact patterns of word-initial German clusters. Journal of Phonetics, 38, 388-403.

Butcher, A. (1977). Coarticulation in intervocalic voiceless plosives and fricatives in connected speech. Arbeitsberichte des Instituts für Phonetik der Universität Kiel (AIPUK), 8, 154-212. 
Byrd, D., \& Choi, S. (2010). At the juncture of prosody, phonology, and phonetics-The interaction of phrasal and syllable structure in shaping the timing of consonant gestures. In C. Fougeron, B. Kühnert, M. D’Imperio, \& N. Vallée (Eds.), Laboratory phonology 10 (pp. 31-59). Berlin: De Gruyter.

Cambier-Langeveld, T. (2000). Temporal marking of accents and boundaries (LOT series 32). Ph.D. dissertation, Amsterdam.

Chatterjee, S., Hadi, A. S., \& Price, B. (2000). Regression analysis by example. New York: John Wiley and Sons.

Cho, T. (2004). Prosodically-conditioned strengthening and vowel-to-vowel coarticulation in English. Journal of Phonetics, 32, 141-176.

Cho, T. (2005). Prosodic strengthening and featural enhancement: Evidence from acoustic and articulatory realizations of /a, i/ in English. Journal of the Acoustical Society of America, 33, 121-157.

Cho, T., \& Jun, S.-A. (2000). Domain-initial strengthening as featural enhancement: Aerodynamic evidence from Korean. Chicago Linguistic Society, 36, 31-44.

Cho, T., \& Keating, P. (2001). Articulatory and acoustic studies of domain-initial strengthening in Korean. Journal of Phonetics, 29, 155-190.

Cho, T., \& Keating, P. (2009). Effects of initial position versus prominence in English. Journal of Phonetics, 37, 466-485.

Cho, T., \& McQueen, J. M. (2005). Prosodic influences on consonant production in Dutch: Effects of prosodic boundaries, phrasal accent and lexical stress. Journa of Phonetics, 33, 121-157.

Choi, H. (2003). Prosody-induced acoustic variation of English stop consonants. In Proceedings of the 15th international congress of phonetic sciences (pp. 26612664), Barcelona, Spain.

Cole, J., Kim, H., Choi, H., \& Hasegawa-Johnson, M. (2007). Prosodic effects on acoustic cues to stop voicing and place of articulation: Evidence from Radio News speech. Journal of Phonetics, 35, 180-209.

Crystal, T. H., \& House, A. S. (1988). Segmental durations in connected speech signals: Current results. Journal of the Acoustical Society of America, 83, 1553-1573.

Dalgaard, P. (2002). Introductory statistics with R. New York: Springer.

Ernestus, M., Lahey, M. F., Verhees, F., \& Baayen, R. H. (2006). Lexical frequency and voice assimilation. Journal of the Acoustical Society of America, 120, 1040-1051.

Farnetani, E., \& Vayra, M. (1996). The role of prosody in the shaping of articulation in Italian CV syllables. In Proceedings of the first ESCA workshop on speech production modeling, fourth speech production seminar, 9-12, 1996, Autrans, France.

Féry, C. (1993). German intonation patterns. Tübingen: Niemeyer.

Fischer-Jørgensen, E. (1976). Some data on North German stops and affricates. Annual Report Institute for Phonetics University Copenhagen (ARIPUC), 10 149-200.

Fougeron, C. (1998). Variations articulatoires en début de constituants prosodiques de different niveaux en francais. Ph.D. dissertation, Université Paris III.

Fougeron, C. (2001). Articulatory properties of initial segments in several prosodic constituents in French. Journal of Phonetics, 29, 109-135.

Fougeron, C., \& Keating, P. A. (1997). Articulatory strengthening at edges of prosodic domains. Journal of the Acoustical Society of America, 101, 3728-3740.

Fox, A. (1993). The prosodic hierarchy in German. In J. L. Flood, P. Salmer, O. Sayce, \& C. Wells (Eds.), Das unsichtbare Band der Sprache. Studies in German Language and Linguistic History in Memory of Leslie Seiffert (pp. 455-481). Stuttgart: Heinz.

Fuchs, S. (2005). Articulatory correlates of the voicing contrast in alveolar obstruent production in German. ZAS Papers in Linguistics (ZASPiL), 41.

Grabe, E. (1998). Comparative intonational phonology: English and German. (MPI Series in Psycholinguistics, 7). Ph.D. dissertation, Nijmegen.

Halle, M., \& Stevens, K. (1971). A note on laryngeal features. Quarterly Progress Report, 101, 198-212.

Jessen, M. (1998). Phonetics and phonology of tense and lax obstruents in German Amsterdam: Benjamins.

Jessen, M. (2001). Phonetic implementation of the distinctive auditory features [voice] and [tense] in stop consonants. In T. A. Hall (Ed.), Distinctive feature theory (pp. 237-294). Berlin: Mouton de Gruyter

Jessen, M., \& Ringen, C. (2002). Laryngeal features in German. Phonology, 19, $189-218$. de Jong, K. (1995). The supraglottal articulation of prominence in English: Linguistic stress as localized hyperarticulation. Journal of the Acoustical Society of America, 97, 491-504.

Jun, S.-A. (1998). The accentual phrase in the Korean prosodic hierarchy. Phonology, $15,189-226$.

Keating, P. A. (1984). Phonetic and phonological representation of stop consonant voicing. Language, 60, 286-319.

Keating, P. A., Cho, T., Fougeron, C., \& Hsu, C.-S. (2003). Domain-initial articulatory strengthening in four languages. In J. Local, R. Ogden, \& R. Temple (Eds.), Papers in laboratory phonology VI (pp. 145-163). Cambridge: Cambridge University Press.

Kohler, K. J. (1977). The production of plosives. Arbeitsberichte des Instituts für Phonetik der Universität Kiel (AIPUK), 8, 30-110.

Kohler, K. J. (1979). Dimensions in the perception of fortis and lenis plosives. Phonetica, 36, 332-343.

Kohler, K. J. (1982). F0 in the production of lenis and fortis plosives. Phonetica, 39 , 199-218.

Kohler, K. J. (1984). Phonetic explanation in phonology. The feature fortis/lenis. Phonetica, 41, 150-174.

Kohler, K. J. (1995). Einführung in die Phonetik des Deutschen (2nd edition). Berlin: Erich Schmidt.

Kuzla, C., Cho, T., \& Ernestus, M. (2007). Prosodic strengthening of German fricatives in duration and assimilatory devoicing. Journal of Phonetics, 35, 301-320.

Kuzla, C., Ernestus, M., \& Mitterer, H. (2010). Compensation for assimilatory devoicing and prosodic structure in German fricative perception. In C. Fougeron, B. Kühnert, M. D’Imperio, \& N. Vallée (Eds.), Laboratory phonology 10 (pp. 731-757). Berlin: De Gruyter.

Lisker, L. (1986). "Voicing" in English: A catalogue of acoustic features signaling /b/ versus /p/ in trochees. Language and Speech, 29, 3-11.

Nakai, S., Kunnari, S., Turk, A., Suomi, K., \& Ylitalo, R. (2009). Utterance-final lengthening and quantity in Northern Finnish. Journal of Phonetics, 37, 29-45.

Nespor, M., \& Vogel, I. (1986). Prosodic phonology. Dordrecht: Foris.

Peterson, G., \& Lehiste, I. (1960). Duration of syllabic nuclei in English. Journal of the Acoustical Society of America, 32, 693-703.

Pierrehumbert, J., \& Talkin, D. (1992). Lenition of $/ \mathrm{h} /$ and glottal stop. In G. J. Docherty, \& D. R. Ladd (Eds.), Papers in laboratory phonology II (pp. 90-117). Cambridge: Cambridge University Press.

de Pijper, J. R., \& Sanderman, A. A. (1994). On the perceptual strength of prosodic boundaries and its relation to suprasegmental cues. Journal of the Acoustical Society of America, 96, 2037-2047.

Piroth, H. G., \& Janker, P. M. (2004). Speaker-dependent differences in voicing and devoicing of German obstruents. Journal of Phonetics, 32, 81-109.

Selkirk, E. (1984). Phonology and syntax: The relation between sound and structure. Cambridge, MA: MIT Press.

Selkirk, E. (1986). On derived domains in sentence phonology. Phonology Yearbook, 3, 371-405.

Shattuck-Hufnagel, S., \& Turk, A. E. (1996). A prosody tutorial for investigators of auditory sentence processing. Journal of Psycholinguistic Research, 25, 193-247.

Slis, I. H., \& Cohen, A. (1969). On the complex regulating the voiced-voiceless distinction II. Language and Speech, 12(80-102), 137-155.

Tabain, M. (2003a). Effects of prosodic boundary on /aC/ sequences: Acoustic results. Journal of the Acoustical Society of America, 113, 516-530.

Tabain, M. (2003b). Effects of prosodic boundary on /aC/ sequences: Articulatory results. Journal of the Acoustical Society of America, 113, 2834-2849.

Turk, A., \& Sawusch, J. R. (1997). The domain of accentual lengthening in American English. Journal of Phonetics, 25, 25-41.

Turk, A., Nakai, S., \& Sugahara, M. (2006). Acoustic segment durations in prosodic research: A practical guide. In S. Sudhoff, D. Lenertová, R. Meyer, S. Pappert, P. Augurzky, I. Mleinek, N. Richter, \& J. Schliesser (Eds.), Methods in empirical prosody research, Vol. 3 (pp. 1-28). Berlin, New York: De Gruyter (=Language, Context, and Cognition.

Ülzmann, N. (2007). Eine experimentalphonetische Analyse des intervokalischen /t-d/ Kontrastes im Norddeutschen. Unpublished M.A. thesis, Kiel University.

Wightman, C. W., Shattuck-Hufnagel, S., Ostendorf, M., \& Price, P. J. (1992). Segmental durations in the vicinity of prosodic phrase boundaries. Journal of the Acoustical Society of America, 91, 1707-1717. 